\title{
Indigenous perspectives on breaking bad news: ethical considerations for healthcare providers
}

\author{
Shemana Cassim, ${ }^{1}$ Jacquie Kidd ${ }_{1}{ }^{2}$ Rawiri Keenan, ${ }^{1}$ Karen Middleton, ${ }^{3}$ Anna Rolleston, ${ }^{4}$ \\ Brendan Hokowhitu, ${ }^{5}$ Melissa Firth, ${ }^{1}$ Denise Aitken, ${ }^{6}$ Janice Wong, ${ }^{3}$ Ross Lawrenson ${ }^{1}$
}

Waikato Medical Research Centre, Division of Arts, Law, Psychology and Social Sciences, University of Waikato, Hamilton, New Zealand

${ }^{2}$ School of Nursing, Auckland University of Technology, Auckland, New Zealand ${ }^{3}$ Respiratory Department, Waikato District Health Board, Hamilton, New Zealand ${ }^{4}$ The Centre for Health, Tauranga, New Zealand ${ }^{5} \mathrm{Te}$ Pua Wananga ki te Ao Faculty of Māori and Indigenous Studies, University of Waikato, Hamilton, New Zealand ${ }^{6}$ Lakes District Health Board, Rotorua, New Zealand

Correspondence to Dr Shemana Cassim, Waikato Medical Research Centre, Division of Arts, Law, Psychology and Social Sciences, University of Waikato, Hamilton 3216,

New Zealand;

shemana.cassim@waikato.ac.nz

Received 16 September 2020 Revised 4 November 2020 Accepted 27 November 2020

\section{Check for updates}

(c) Author(s) (or their employer(s)) 2021. No commercial re-use. See rights and permissions. Published by BMJ.

To cite: Cassim S, Kidd J Keenan R, et al. J Med Ethics Epub ahead of print: [please include Day Month Year] doi:10.1136/

medethics-2020-106916

\section{ABSTRACT}

Most healthcare providers (HCPs) work from ethical principles based on a Western model of practice that may not adhere to the cultural values intrinsic to Indigenous peoples. Breaking bad news (BBN) is an important topic of ethical concern in health research. While much has been documented on BBN globally, the ethical implications of receiving bad news, from an Indigenous patient perspective in particular, is an area that requires further inquiry. This article discusses the experiences of Māori (Indigenous peoples of New Zealand) lung cancer patients and their families, in order to investigate the ethical implications of receiving bad news. Data collection occurred through 23 semistructured interviews and nine focus groups with Māori lung cancer patients and their families in four districts in the Midland Region of New Zealand: Waikato, Bay of Plenty, Lakes and Tairāwhiti. The findings of this study were categorised into two key themes: communication and context. Avenues for best practice include understanding the centrality of the HCP-patient relationship and family ties in the healthcare journey, and providing patients with the full range of viable treatment options including hope, clear advice and guidance when the situation calls for it. Overall, the findings of this study hold implications for providing culturally safe and humanistic cancer care when BBN to Māori and Indigenous patients.

\section{INTRODUCTION}

Most healthcare providers (HCPs) work from ethical principles based on a Western model of practice, and the Hippocratic tradition. Many Indigenous cultures, however, have a very different framework of values that need to be taken into account in medical care. Breaking bad news (BBN) is an important topic of ethical concern in the fields of health research and medical education. BBN involves delivering bad, serious or significant news to patients and whānau (family), and can include test results or diagnoses of long-term or life-altering conditions. ${ }^{1}$ Overall, HCPs are driven by an ethical imperative to do good by their patients. Historically, the paternalistic patient-care model involved the HCP acting as the patient's guardian, and delivering only selected information that steered the patient to what the HCP considered was the best decision. ${ }^{2}$ Since then, there has been a turn in focus towards patient-centred care. As such, various expert consensus guidelines were published to aid HCPs in BBN. ${ }^{1}{ }^{3} 4$ The more prominent protocols or guidelines to support best practice in BBN include ABCDE, ${ }^{5}$ BREAKS, ${ }^{6}$ Kayes 10 steps, ${ }^{7}$ Girgis and Sanson-Fischer's consensus guidelines and best practices $^{38}$ and SPIKES. ${ }^{9}$ In oncology, SPIKES is the most widely used protocol in guidance, ${ }^{10}$ teaching programmes ${ }^{11}$ and by HCPs in practice. ${ }^{12}$ Themes common to all these guidelines involve finding an appropriate setting, establishing rapport, assessing the patient's previous knowledge of the condition, their wish for more information, avoiding medical jargon, supporting patients' emotions, allowing for questions, summarising and discussing the next steps.

The experiences of BBN from both HCP and patient perspectives have been extensively documented. ${ }^{3479} 1013-23$ However, the ethical dilemmas relating to BBN have only received scant attention. The research in this area tends to mostly focus on HCP perspectives, discussing topics such as patient privacy, autonomy, informed consent, truth-telling and full-disclosure. ${ }^{24-31}$ The ethical implications of receiving bad news, from a patient and whānau perspective in particular, is an area that warrants further inquiry.

This article has two main aims. First, we explore the ethical implications of receiving bad news from a general patient perspective. Second, more specifically, we discuss the ethical implications of Māori (Indigenous peoples of New Zealand (NZ)) lung cancer patients and their whānau receiving bad news. Briefly, Māori models of health exist and are well known within the Aotearoa health system. ${ }^{32} 33$ The most commonly used model is Mason Durie's Te Whare Tapa Wha ${ }^{34}$ which describes a holistic model of health comprising the realms of tinana (physical), hinengaro (mental and emotional), whānau (family) and wairua (spiritual) health. It is also important to note here, that in the present context, 'bad news' included a lung cancer diagnosis, as well as test results (eg, X-ray, CT scan, PET scan, etc), delivered by various HCPs including general practitioner (GPs) and secondary care physicians, nurses and specialists.

\section{METHODS}

\section{Recruitment and data collection}

Data collection occurred through qualitative interviews and community hui $(\mathrm{CH})$ (meetings/ focus groups) with Māori lung cancer patients and whānau in four districts in the Midland Region of NZ (comprising both rural and urban localities): Waikato, Bay of Plenty, Lakes and Tairāwhiti.

Semistructured interviews were carried out with a total of 23 Māori lung cancer patients and whānau (comprising 16 patients, and 7 whānau members). Nine participants were male, and 14 were female. Patient recruitment was carried out by respiratory or cancer nurse specialists based at the hospitals of 
each district. Interviews were carried out by a Māori researcher, and were 1-2 hours in duration. Interviews commenced with whakawhanaungatanga (building connections between the interviewer and participants), and often opened and closed with karakia (prayer).

$\mathrm{CH}$ were carried out in five rural localities within the four districts mentioned previously. All $\mathrm{CH}$ were organised in conjunction with key Māori stakeholders in each community, followed local tikanga (protocols), and were led by Māori members of the team. Participants were recruited using 'snowball' sampling (see work by Kidd et al) ${ }^{35}$ for further details of the community engagement process). A total of nine $\mathrm{CH}$ were carried out, each comprising between 8 and 21 participants, which included patients with cancer, whānau and other community members affected by (lung) cancer.

\section{Analysis}

Interview and hui data were recorded via an audio recorder and as field notes. Audio recordings were transcribed and anonymised. Pseudonyms were used to maintain anonymity of interview participants. Transcripts and field notes were thematically analysed. ${ }^{36}$ Analysis was carried out by SC and JK independently and then together, to ensure a rigorous analysis process. Findings were categorised into two broad themes: communication and context.

\section{FINDINGS}

\section{Communication}

Communication by the HCP was a key theme discussed by all participants, and involved how the diagnosis and treatment options were delivered to patients with lung cancer and their whānau. Our findings highlighted three subthemes relating to communication, which involved providing an array of options and clear advice, giving patients and whānau hope, and the use of analogies and simple language.

\section{Options and clear advice}

Participants indicated that when discussing their diagnosis and treatment, it was important that they were presented with as many options as possible, so they could collectively discuss and decide on the next steps on their lung cancer journey. For instance, participants in $\mathrm{CH}$ would have appreciated a 'smorgasbord' of options to be presented to them and their whānau, without having to specifically ask for it:

\begin{abstract}
A: All [patients] want to hear about is how the hell am I gonna get cured? Because that's what I asked when my wife was diagnosed. Give us a smorgasbord of opportunity. The person who was there with me was meant to be a liaison person, said oh but it's too expensive. And I said, I'm not talking to you. Because I was looking for the best-for health. Price shouldn't be of any consequence. B: I think it's about letting us have those options. And how can that smorgasbord be spread before me without me having to make a special case for it. ( $\mathrm{CH \# 4)}$
\end{abstract}

Moreover, when the diagnosis and treatment options are delivered, Māori patients indicate that the provision of clear advice and direction are important to them. Participants in another $\mathrm{CH}$, for instance, compared the communication styles of the two specialists who discussed treatment options with them following diagnosis:

With that initial meeting with the two surgeons, one surgeon is a professional-explained to us our options. We didn't know nothing. Thank god for the other surgeon. Because in order to follow without committing himself illegally, he gave us enough ideas about what action to take. And we were so grateful. We were there for clarity. Not following a checklist or some standard procedure. We didn't know where to go, or who to turn to. But at that initial meeting we got direction. He was very clear. And we took that advice. ( $\mathrm{CH \#} \mathrm{6)}$

\section{Hope}

Giving hope was an important aspect of delivering (or receiving) bad news to Māori lung cancer patients and whānau. Many participants were diagnosed with late stage, often palliative lung cancer. Thus, while many were aware that their cancers were incurable, their oncology specialist telling them that there is nothing else they can do, was unhelpful:

\section{My husband had 3 rounds of Chemo and it didn't work, and then they said 'sorry'. That was pretty blunt. 'Sorry, can't do anything else'. What really annoyed me was after being with them for that long, they didn't have anything else. They didn't even refer you to anything natural. To give it a go. Cause what have we got to lose? Where does he go from here? Give us some hope. It was old Google that helped us in the end. We got on there and had a look at what was being offered naturally. $(\mathrm{CH \#} 6)$}

This account builds on the previous theme, where the options presented by the HCP could include alternative treatments such as natural remedies or rongoā (traditional Māori treatments) to make the patient comfortable, ease their pain and most importantly, to give them hope. Despite being at the 'end of the road', how an HCP communicates this message can significantly ease patient and whānau stress, and can improve quality of life in the time they have left.

\section{Analogies and simple language}

The use of analogies and simple language can also be instrumental in easing stress of the diagnosis and prognosis for patients and whānau. Moana's daughter relates how their specialists explained her lung cancer diagnosis and treatment clearly to them, using common analogies in a way that they could visualise and understand what was going on:

We were told [Mum is] at stage IV, which means it's not curable and [we got a] really good explanation. The reason why it's not curable is because it's not a single cell or solo lump that can be operated on and removed. ...It had little highway nodes to other parts of the body and therefore you can operate and try and get it out, but history has taught that it causes more problems because the cancer has already spread-finds new highways and spreads even more. However, we can treat it to make sure that the cancer doesn't spread anymore or grow and really improve the quality of life. In reality it's totally understandable to hear these words, because we want to hear the truth... [They also said] that infusion Chemotherapy acts like a weed killer. And like a weed killer you could spray it on the weed... and it kills the weed but unfortunately it damages other things in its path and can hurt other things as well. (Moana's daughter, female, Waikato)

Honesty and simple, relatable language were important, and appreciated by Moana and her whānau, despite finding out that the cancer was at stage IV and incurable.

\section{Context}

The delivery of a diagnosis can vary considerably based on the situation. For instance, patients may want to know their 
diagnosis as quickly as possible. Conversely, others may not be ready for their diagnosis, and want to gather whānau to hear the news. HCPs need to adapt their style of delivery based on different patient realities. Accordingly, our findings highlighted two subthemes relating to context: proactive patients and the role of whānau.

\section{Proactive patients}

Keerehi was very eager to hear the results of her CT scan, and promptly arranged an appointment with her GP, who did not have time to prepare for the delivery of bad news:

\begin{abstract}
After the CT scan... the GP knew nothing about it! It was because I'd pushed for them to come straight to the GP and as soon as they turned up there I rang the GP.I walked into the room, she sat there and she goes 'what can I do for you today [Keerehi]?' And I said to her, you can read those CT results up on your screen and tell me what the story is? Anyway she spins around, looked at it for a couple of minutes and then she turned back to me... she was lovely, I mean, I take my hat off to her... she said, '[Keerehi] would you like me to get someone to ring for you? To be with you?' And I said 'no, I've been waiting for 2 weeks for this, you might as well tell me now'. And she even had tears in her eyes telling me. She wasn't expecting to be telling me that. (Keerehi, female, Waikato)
\end{abstract}

Here, despite being caught off-guard, the HCP adapted to the situation and delivered her test results in a manner that was was greatly appreciated by Keerehi. Here, the GP seems to have acted with care and compassion towards Keerehi.

\section{Role of whānau}

Having whānau actively participate with the patient has implications in terms of patient privacy, particularly in mainstream medical care from a predominantly 'Western' approach. However, for Māori patients, whānau play a key role in any health journey. Rewi's whānau, for instance, served as mediators who relayed his late-stage lung cancer diagnosis to him, as Rewi had difficulty listening to and receiving this information:

Rewi Aw it pisses you off doesn't it. You don't know where you stand. And they think you's gonna like sit there and listen. Obviously not. You've got other things in mind. I was like aw well I'm outta here!

Son: We just kinda keep him positive. And we gave him as much information and do as much as we can for him. 'Cause you know he gets a little tongue tied sometimes... this is your worst day and like he's repeating himself over the same things. So we're coming in and finding out what the doctor's talking about and try and get them to understand from his point of view (Rewi and his son, Waikato)

As Rewi's son points out, the day a patient receives a palliative lung cancer diagnosis becomes the 'worst day' in their life. Therefore, some patients not only struggle with their diagnosis, but also refuse to receive it. In such contexts, HCPs can follow the whānau member or carer's directive on how to proceed. At a $\mathrm{CH}$, the wife of a patient explains how she bore the burden of receiving the bad news and relaying it to her husband, who was not ready to hear it from the specialist:

Sometimes [my husband] didn't want to hear the bad news, but I knew 'cause I knew him inside out. So I would leave the room [with the HCPs], and said so what's going on? So they would share that with me. (CH\#6)

Additionally, when delivering bad news, including whānau in the discussion is important. Here, the individual patient's health is seen as being connected with the health of the whānau. Therefore, when bad news is delivered, it impacts on the whole whānau and thus, HCPs need to have care and compassion for everyone who is present for that conversation::

As a [doctor] the first thing you do is start talking to the patient. And tell them you need to do this and this. But they don't talk to the whānau that are sitting there. Telling the whānau that [my wife has] got lung cancer, this is what's gonna happen, you know? That kind of thing can help the whānau. Explain it to them, and making sure that you're not only talking to the patient but to the family there with them as well. And giving something that the family can understand. (Keerehi's husband, male, Waikato)

...the whole tikanga within, within the process... Knowing that we come with many whānau members, children, aunties, uncles, everybody wants to come... they need to be there and their koros [grandfathers], their nans they need them there.... Because this is part of your healing process, this is what is going to make it better for you. (CH\# 1)

Participants also highlighted that within a predominantly 'Western' healthcare space, it is whānau who ensure that tikanga is followed, and who look after the wairua (spirit/soul) of (particularly elderly) patients by ensuring that their mana (authority/status) is respected and maintained. At a $\mathrm{CH}$, participants discussed the importance of having whānau support to fill the gap, or address the discrepancy in mainstream healthcare:

If you are tūturu to your Māori-ness [everything is subsumed by your Māori identity], you know that the whānau looks after their own... Their [HCP] job is to look after the tinana [body], but you need to look after the wairua too. Because that's what keeps the person going $(\mathrm{CH \#} \mathrm{2)}$

Overall, for Māori, whānau play a central role in, and are as much a part of the lung cancer journey as patients.

\section{DISCUSSION}

The findings of this study are consistent with BBN guidelines such as SPIKES, ${ }^{9}$ and extend this knowledge by exploring ethical dilemmas in the specific context of Māori lung cancer patients and whānau. As such, our findings demonstrate that while all the ethical dilemmas raised are important specifically for Māori (and potentially also relevant to other Indigenous communities), many of these concerns may also be relevant to all patients in general. Parallels with existing guidelines include the importance of simple language that are likely useful when interacting with all patients, and HCPs understanding how whānau are placed in the interaction that are important specifically to Māori and Indigenous communities, but also more generally applicable in some contexts. Key areas for additional discussion include communication and context.

Providing patients with clear advice, direction and hope were three key points raised, relating to communication. It is important to note that the establishment of connection (whakawhanaungatanga) is a vital first step in communication for Māori patients and whānau which has been well described elsewhere. ${ }^{37} 38$ When receiving bad news, first the delivery of clear information and advice to patients is vital to ensure they understand what is being communicated and to adjust language and the pace of delivery accordingly. Regular checking back with patients and whānau can help ensure they understand the information delivered to them. In NZ, culturally tailored models of communication such as the Hui Model ${ }^{39}$ or the Meihana Model ${ }^{40}$ have been developed to assist HCPs. Whakawhanaungatanga is also a key part 
of the GP-patient relationship, where trust and safety is established. This is important, as the GP is often a patient's first point of contact when receiving a diagnosis or test results. Similarly, we also wish to highlight the ethical significance of 'care and compassion' shown by HCPs towards their patients when delivering bad news. Most importantly, an HCP needs to be able to understand how to be caring and compassionate with patients in general, and with Indigenous patients in particular, where their Indigeneity is an important aspect of the context.

HCPs need to balance their patients' rights to involvement and choice in their treatment with the desire many have for direction at a critical and traumatic time in their lives. Participants indicate that giving direction is not perceived as coercion. Rather, Māori place a lot of trust in, and respect their HCPs as the expert, ${ }^{41-43}$ and as such seek guidance and direction from them. In saying this, it is also important to note that patients may want choice. Therefore, guidance and advice also involves providing patients with a 'smorgasbord' of options about the next steps. One area of controversy is whether patients should be advised of scientifically proven options that are not available in the public health system due to cost. HCPs (often oncologists) have to navigate the balance between deciding whether or not the patient can afford certain treatment options and raising expectations that may not be realised, so that patients are not left disappointed that they cannot access expensive drugs or treatments. In the NZ context, oncologists are obliged by the Health and Disabilities Commission to provide full disclosure around what the patients and whānau may benefit from. HCPs should establish whether patients are insured or can otherwise cope with the costs of nonstandard treatments when broaching this topic. Sometimes it appears that assumptions about patients' circumstances are made based on appearance, ethnicity or job status. ${ }^{44}$ Clear communication and transparency are key to avoid misunderstandings or misplaced assumptions.

Third, even in the face of mortality, Māori patients and whānau seek some degree of hope from their HCP. Given that for Māori communities specifically, cancer tends to be associated with a death sentence, due to past experiences with whānau members, and the overall inequity in health outcomes ${ }^{45}$ patients require some form of reassurance and hope from HCPs. However, the issue of hope may also be relevant to all patients, rather than being specific only to Māori. Nonetheless, such instances raise the question: is it ethical to give patients seemingly 'unrealistic' hope? Certainly, the literature discussing 'truth-telling' often indicates that optimal supportive medical care requires honesty, full disclosure and for HCPs to allow patients the chance to finalise affairs and say their goodbyes. ${ }^{24}$ Yet, as Whitney et $a l^{46}$ demonstrates, HCPs can maintain an open-ended hopefulness, or offer hope to help patients day-to-day such as natural remedies to ease nausea or pain from treatment. Here, while HCPs may be cautious about the ethics of offering unproven treatment options to patients, it is important to bear in mind that Māori perceptions of health are holistic, and go beyond physical health to also encompass spiritual health (wairuatanga) and connections to the natural world. ${ }^{32} 34$ Thus, when working with Indigenous peoples, HCPs need to consider holistic, natural and spiritual wellness alongside physical outcomes. Overall, providing patients with an array of options to promote holistic wellness is also compatible with an HCP's obligation to be truthful, and still convey support and caring. Thus, an HCP's awareness of the roles of hope and hopefulness can help sustain patients and whānau as they adapt to the reality of a palliative illness. ${ }^{46}$

Context was the second theme derived from our findings, and encompassed issues such as the role of whānau and patient's privacy. Whānau play an important role in a Māori patient's cancer care journey, where patient and whānau should be considered as one, rather than as separate units when delivering bad news. Moreover, despite mainstream 'Western-centric' medical ethics dictating that a patient's individual right to privacy takes precedence, when working with Māori, HCP's may find themselves having to follow the lead or direction of whannau members when BBN. Non-disclosure of a diagnosis based on whānau request has been discussed in-depth as an ethical issue in previous research, particularly in 'non-Western' and Indigenous contexts. For instance, HCPs felt that non-disclosure carried high psychological costs for patients and whānau. ${ }^{24}$ However, medical ethics research from non-Western and/or migrant contexts recognise that this is not an issue of lying to patients or withholding information. Rather, it is about respecting the cultural contexts of patients and whānau. ${ }^{24} 4849$ Ultimately, the HCP finds themselves having to reflect and adapt to the (cultural) context of the interaction, and respond in the best interests of the patient and whānau. Importantly, the participants in this study did not advocate for non-disclosure but rather sought to mitigate the trauma of receiving the bad news by delivering it to whānau to act as intermediaries. This, of course, relies on the HCP having established a clear communication process with the patient and whānau in order to effectively assess the most appropriate way to deliver the news.

Overall, the findings of the present study hold implications for providing culturally safe and humanistic cancer care when BBN to Māori and Indigenous patients. However, while the findings indicate that ethical concerns arise in the context of culture, reflecting specifically Māori beliefs and conceptual structures, parallel concerns and experiences might also be found in patient experiences in general. Avenues for best practice include understanding the centrality of the HCP-patient relationship, and providing patients and whānau with the full range of viable treatment options alongside providing hope, clear advice and guidance when the situation calls for it. Additionally, building on existing BBN guidelines, HCPs should consider whānau an equally important a part of the patient-care journey. HCPs could also engage in ongoing reflective practice to hold themselves accountable for providing culturally safe, family-centred care. ${ }^{50} 51$ More broadly, HCPs and medical educators need to emphasise the cultural context of their patients when considering how to break bad news.

This research had several strengths and limitations. The strengths include our focus on ethical dilemmas relating to Indigenous patients and their families. A limitation of this study was its focus on patients with lung cancer and only on Indigenous peoples of NZ. Future research could investigate the experiences of patients from other culturally diverse groups and those with other forms of cancer or chronic disease to gain a more comprehensive understanding of patient perspectives of receiving bad news. The findings of this study are most applicable to HCPs working in NZ, but they can also be relatable and applicable to HCPs working with other Indigenous and culturally diverse groups globally.

\section{Twitter Rawiri Keenan @DrRawiri}

Acknowledgements He tino honore mātou e whakanui ana mātou te kaupapa Hā Ora ki ngā iwi e whakatinana, e whakaora ai tēnei kaupapa ā Hā Ora ki a rātou kōrerorero. Kā whakawhetai mātou ki ngā whānau e kōrero ana te kōrero e hīkoi ana te hīkoi ki tēnei huarahi, kahuri kia rātou hoki e wehi atu ki rangi whetu ma ki tua o te ārai ano kia rātou e ora tonu ai me ngā uri e heke mai nei, nōreira he honore ano i a mātou ki te whakanui ēnei rangatira me à rātou whānau ki a whiri whiri ā rātou kōrero kia tau te rangimarie, te aroha me te whakapono Paimarire. We are very honoured to acknowledge those who shared their stories and brought 
to life Hā Ora. We are forever thankful and dedicate this to them and their families for embracing Hā Ora. For talking the talk and walking the walk. To those who have passed on, who reside among the many stars of the heavens, to those living who remain with us, and for the generations to come. Again, it is indeed a great honour for us to acknowledge these rangatira and their families. May peace, love and faith keep you safe. Paimarire.

Contributors All authors have contributed significantly to this manuscript. SC: acquisition of data, interpretation of data, manuscript writing and revision. JK: original conception and design of study, acquisition of data, interpretation of data, manuscript writing and revision, RK: original conception and design of study, manuscript revision. KM: original conception and design of study, manuscript revision. AR: original conception and design of study, acquisition of data, manuscript revision. BH: original conception and design of study, manuscript revision. MF: original conception and design of study, manuscript revision. DA: original conception and design of study, manuscript revision. JW: original conception and design of study, manuscript revision. RL: original conception and design of study, manuscript writing and revision. All authors read and approved the final manuscript.

Funding This project was funded by the Health Research Council of New Zealand (HRC grant number 17/438, entitled 'Improving early access to lung cancer diagnosis for Māori and Rural Communities').

Disclaimer The funding body did not play a role in the design of the study and collection, analysis, and interpretation of data and in writing the manuscript.

Competing interests None declared.

Patient consent for publication Not required.

Ethics approval This project received ethical approval from the Health and Disabilities Ethics Committees (HDEC) of New Zealand - Ref 17/STH/158.

Provenance and peer review Not commissioned; externally peer reviewed.

Data availability statement All data relevant to this study are included in the article.

\section{REFERENCES}

1 Berkey FJ, Wiedemer JP, Vithalani ND. Delivering bad or Life-Altering news. Am Fam Physician 2018;98(2):99-104.

2 Emanuel EJ, Emanuel LL. Four models of the physician-patient relationship. JAMA 1992;267(16):2221-6.

3 Girgis A, Sanson-Fisher RW. Breaking bad news. 1: current best advice for clinicians. Behav Med 1998:24(2):53-9.

4 Randall TC, Wearn AM. Receiving bad news: patients with haematological cancer reflect upon their experience. Palliat Med 2005;19(8):594-601.

5 Rabow MW, McPhee SJ. Beyond breaking bad news: how to help patients who suffer. West J Med 1999;171(4):260-3.

6 Narayanan V, Bista B, Koshy C. 'BREAKS' protocol for breaking bad news. Indian J Palliat Care 2010;16(2):61-5

7 Kayes P. Breaking bad news: a 10 step approach. Northampton: EPL Publications, 1996.

8 Girgis A, Sanson-Fisher RW. Breaking bad news: consensus guidelines for medical practitioners. J Clin Oncol 1995;13(9):2449-56.

9 Baile WF, Buckman R, Lenzi R, et al. SPIKES-A six-step protocol for delivering bad news: application to the patient with cancer. Oncologist 2000;5(4):302-11.

10 Seifart C, Hofmann M, Bär T, et al. Breaking bad news-what patients want and what they get: evaluating the spikes protocol in Germany. Ann Oncol 2014;25(3):707-11.

11 Baer AN, Freer JP, Milling DA, et al. Breaking bad news: use of cancer survivors in role-playing exercises. J Palliat Med 2008;11(6):885-92.

12 Morgans AK, Schapira L. Confronting therapeutic failure: a conversation guide. Oncologist 2015;20(8):946-51.

13 Ellis PM, Tattersall MH. How should doctors communicate the diagnosis of cancer to patients? Ann Med 1999;31(5):336-41.

14 Ptacek JT, Eberhardt TL. Breaking bad news. A review of the literature. JAMA 1996;276(6):496-502.

15 Charlton RC. Breaking bad news. Med J Aust 1992;157(9):615-21.

16 Fallowfield L. Giving sad and bad news. Lancet 1993;341(8843):476-8.

17 Campbell ML. Breaking bad news to patients. JAMA 1994;271(13):1052.

18 VandeKieft GK. Breaking bad news. Am Fam Physician 2001;64(12):1975-8.

19 Quill TE, Townsend P. Bad news: delivery, dialogue, and dilemmas. Arch Intern Med 1991;151(3):463-8
20 Mirza RD, Ren M, Agarwal A, et al. Assessing patient perspectives on receiving bad news: a survey of 1337 patients with life-changing diagnoses. AJOB Empir Bioeth 2019;10(1):36-43.

21 Fujimori M, Uchitomi Y. Preferences of cancer patients regarding communication of bad news: a systematic literature review. Jpn I Clin Oncol 2009;39(4):201-16.

22 Sobczak K, Leoniuk K, Janaszczyk A. Delivering bad news: patient's perspective and opinions. Patient Prefer Adherence 2018:12:2397-404.

23 Yardley SJ, Davis CL, Sheldon F. Receiving a diagnosis of lung cancer: patients' interpretations, perceptions and perspectives. Palliat Med 2001;15(5):379-86.

24 Chittem M, Butow P. Responding to family requests for nondisclosure: the impact of oncologists' cultural background. J Cancer Res Ther 2015;11(1):174-80.

25 Rogg L, Aasland OG, Graugaard PK, et al. Direct communication, the unquestionable ideal? oncologists' accounts of communication of Bleak prognoses. Psychooncology 2010;19(11):1221-8.

26 Barnes DM, Davis AJ, Moran T, et al. Informed consent in a multicultural cancer patient population: implications for nursing practice. Nurs Ethics 1998;5(5):412-23.

27 Hurst SA, Baroffio A, Ummel M, et al. Helping medical students to acquire a deeper understanding of truth-telling. Med Educ Online 2015;20:28133-4.

28 Gordon EJ, Daugherty CK. 'Hitting you over the head': oncologists' disclosure of prognosis to advanced cancer patients. Bioethics 2003;17(2):142-68.

29 Oliffe J, Thorne S, Hislop TG, et al. "Truth telling" and cultural assumptions in an era of informed consent. Fam Community Health 2007;30(1):5-15.

30 Hamadeh GN, Adib SM. Cancer truth disclosure by Lebanese doctors. Soc Sci Med 1998:47(9):1289-94.

31 Hoff L, Tidefelt U, Thaning L, et al. In the shadow of bad news - views of patients with acute leukaemia, myeloma or lung cancer about information, from diagnosis to cure or death. BMC Palliat Care 2007;6:1-2.

32 Durie MH. Te Pae Māhutonga: a model for Māori health promotion. Health Promotion Forum of New Zealand Newsletter 1999:49.

33 Durie M. Whaiora: Māori health development. Auckland, New Zealand: Oxford University Press, 1994

34 Durie MH. Te Whare Tapa Whā: a Māori perspective of health. Social Science \& Medicine 1985;20(5):483-6

35 Kidd J, Cassim S, Rolleston A, et al. Hā Ora: Reflecting on a Kaupapa Māori community engaged co-design approach to lung cancer research. Int J Indig Health. In press

36 Braun V, Clarke V. Successful qualitative research: a practical quide for beginners. London: SAGE, 2013.

37 Carlson T. Whanaungatanga: a space to be ourselves. J Indig Wellbeing 2016:1(2):44-59.

38 Slater T, Matheson A, Davies C, et al. 'It's whanaungatanga and all that kind of stuff': Maori cancer patients' experiences of health services. J Prim Health Care 2013;5(4):308-14.

39 Lacey C, Huria T, Beckert L, et al. The Hui process: a framework to enhance the doctorpatient relationship with Māori. N Z Med J 2011:124(1347):72-8.

40 Pitama S, Huria T, Lacey C. Improving Maori health through clinical assessment: Waikare 0 te Waka 0 Meihana. N Z Med J 2014;127(1393):107-19.

41 Jansen P, Bacal K, Crengle S. He ritenga whakaaro: Māori experiences of health services. Auckland, New Zealand: Mauri Ora Associates, 2008.

42 Walton L, McNeill R, Stevens W, et al. Patient perceptions of barriers to the early diagnosis of lung cancer and advice for health service improvement. Fam Pract 2013;30(4):436-44.

43 Kidd Jet al. Hā Ora: secondary care barriers and enablers to early diagnosis of lung cancer for Māori communities. BMC Cancer.

44 Walker T, Signal L, Russell M, et al. The road we travel: Māori experience of cancer. $N$ Z Med J 2008:121(1279):27-35

45 Cassim S, Kidd J, Rolleston A. Hā Ora: barriers and enablers to early diagnosis of lung cancer in primary healthcare for Māori communities. Eur J Cancer Care 2021:e13380.

46 Whitney SN, McCullough LB, Frugé E, et al. Beyond breaking bad news: the roles of hope and hopefulness. Cancer 2008;113(2):442-5.

47 Mark G, Koea J. Identifying Rongoā Māori healing and medical health collaboration issues: a thematic synthesis review. Auckland, New Zealand: Health Research Council, 2019

48 Goldstein D, Thewes B, Butow P. Communicating in a multicultural Society II: Greek community attitudes towards cancer in Australia. Intern Med J 2002;32(7):289-96.

49 Fujimori M, Akechi T, Akizuki N, et al. Good communication with patients receiving bad news about cancer in Japan. Psychooncology 2005;14(12):1043-51.

50 Medical Council of New Zealand. Statement on cultural safety, 2019. Available: https://www.mcnz.org.nz/our-standards/statements-definitions-and-publications/ [Accessed 28 May 2020].

51 Medical Council of New Zealand. Statement on best practices when providing care to Maori patients and their whanau, 2006. Available: https://www.mcnz.org.nz/ourstandards/statements-definitions-and-publications/ [Accessed 19 May 2020]. 